\title{
Migração RTM 3D do Registro de Múltiplas Fontes com Riqueza Azimutal Aplicada ao Modelo Overthrust SEG/EAGE
}

Josias José da Silva ${ }^{1}$, Djalma M. S. Filho ${ }^{2}$, Bruno M. da Silva ${ }^{1}$ e Luiz Landau ${ }^{1}$

${ }^{1}$ Laboratório de Modelagem Multidisciplinar de Bacias Sedimentares - LAB2M/COPPE/UFRJ

${ }^{2}$ CENPES /PETROBRAS

Copyright 2006, SBGf - Sociedade Brasileira de Geofísica

Este texto foi preparado para a apresentação no II Simpósio de Geofísica da Sociedade Brasileira de Geofísica, Natal, 21-23 de setembro de 2006. Seu conteúdo foi revisado pela Comissão Tecno-científica do II SR-SBGf mas não necessariamente representa a opinião da SBGf ou de seus associados. E proibida areprodução total ou parcial deste material para propósitos comerciais sem prévia autorização da SBGf.

\section{Resumo}

A migração reversa de tempo (RTM - "reverse time migration") está entre as ferramentas mais indicadas para o imageamento em profundidade de estruturas geológicas complexas. Suas suposições são simples o bastante para fazê-la recomendada nos casos onde haja grandes variações laterais de velocidade. Entretanto, utilizando metodologias tradicionais, onde cada registro de tiro comum é migrado separadamente, sua aplicabilidade diante dos grandes volumes de dados de um levantamento sísmico 3D torna-se impraticável. A fim de tornar factível a aplicação da migração reversa no tempo ante aos recursos computacionais existentes, alguns autores propuseram o esquema de registro de múltiplas fontes -ou areal shot gather - (Berkhout, 1992; Cunha, 2002 e Zhang et al., 2003), onde todos os registros de tiro comum são somados em um supersismograma e, então, migrado uma única vez. Neste trabalho serão mostrados os resultados da aplicação da técnica RTM para o registro de múltiplas fontes de uma aquisição $3 \mathrm{D}$ com riqueza azimutal com o objetivo de imagear as estruturas complexas do modelo Overthrust da SEG/EAGE. Foi utilizado o método de diferenças finitas para discretização da equação completa da onda com aproximações de segunda ordem para as derivadas parciais temporais e quarta para as derivadas espaciais.

\section{Introdução}

As grandes companhias de petróleo no mundo enfrentam $o$ desafio de encontrar reservas de hidrocarbonetos em estruturas geológicas cada vez mais complexas. Muitas técnicas de imageamento sísmico têm sido desenvolvidas com este objetivo, principalmente quando tratamos de resolução abaixo de domos salinos. A sísmica $3 \mathrm{D}$ é uma ferramenta de grande potencial cujo poder de resolução está fornecendo novos entendimentos dentro dos processos geológicos (Zeitlin, 2001). No entanto, o grande volume de dados gerados neste tipo de aquisição obriga a indústria a utilizar não a técnica que fornece a melhor resolução e sim a que é computacionalmente viável. Neste momento, um papel de extrema importância está no desenvolvimento de tecnologias que tornem as técnicas de imageamento aplicáveis ao grande volume de dados gerados na exploração petrolífera tridimensional.

A migração RTM convencional utilizada hoje na indústria do petróleo é feita a partir do domínio do tiro ou receptor comum. Tal migração é estabelecida a partir do teorema da reciprocidade da função de Green. De uma forma simplificada pode-se dizer que o método da migração reversa no tempo se resume a um problema de condição contorno associado a uma condição de imagem, onde a condição de contorno é o registro do campo de pressão feito na superfície pelos geofones ou hidrofones e, a condição de imagem é o tempo de trânsito da onda direta para cada posição do modelo. Desta forma, o sismograma registrado na superfície é re-injetado no modelo do tempo final $\left(t_{f}\right)$ até ao tempo inicial $(t=0)$. Uma das suas principais vantagens é que neste método pode-se utilizar a equação da onda completa (Cunha, 2003), com isto, pode-se migrar refletores com qualquer inclinação, entretanto, para se evitar reflexões múltiplas originadas no processo de migração, é necessário que a depropagação do campo se faça em apenas uma direção. Para isso, o modelo de impedância acústica deve ser suavizado. Quando se considera densidade constante, esta suavização pode ser realizada sobre o campo de vagarosidade $(=1 / \mathrm{vel})$ (Faria, 1986). Outra vantagem é que a migração RTM apresenta bons resultados em modelos complexos com grandes variações laterais de velocidade. A desvantagem é que apesar dos clusters de computadores utilizados hoje em 
dia, o processo é custoso em termos de velocidade de processamento.

O objetivo deste trabalho é de aplicar o conceito de múltiplas fontes introduzido por Berkhout (1992), Faria (1986) e Cunha (2003) em um modelo geológico complexo 3D. A diferença neste tipo de simulação é que os sismogramas para cada tiro são somados antes da migração produzindo um supersismograma. Matematicamente, podemos nos basear no princípio de Huygens para dizer que este procedimento simula uma onda plana que se desloca ao longo do modelo. Todo o processo de imageamento deve então ser feito considerando esta onda plana. Por exemplo, os tempos da chegada da onda direta em cada posição da malha (TD's) são calculados um única vez para migração de cada família de tiros. O modelo de velocidade utilizado foi o Overthrust. Este foi concebido a partir dos esforços de geólogos, geofísicos e cientista da computação de mais de cinqüenta organizações mundiais em um projeto conjunto entre a SEG e a EAGE. O modelo de velocidade suavizado foi utilizado para a realização do cálculo da onda direta (condição de imagem associada à primeira chegada) e para o processo de depropagação dos dados na migração. A forma de determinação dos tempos de chegada da onda direta foi realizada de acordo com o proposto por Silva (2002), onde se considera a variação temporal da amplitude da primeira quebra com o objetivo de retirar os artefatos normalmente encontrados quando apenas registramos a máxima amplitude do campo de onda (Botelho e Stoffa, 1988). A geometria e o modelo de velocidade foram criados para produzir um dado sísmico complexo que exijam técnicas de processamento avançadas para o correto imageamento das estruturas. Os parâmetros do modelo e os utilizados na simulação estão listados na Tabela 1.

\section{RTM para famílias de múltiplas fontes}

Denotando por $\hat{u}\left(x, y, z=0, t ; f_{n}\right)$ o sismograma relativo a detonação na posição $f_{n}(x, y)$ e $\tilde{u}(x, y, z=0, t ; p)$ uma família de múltiplas fontes, a migração RTM para esse conjunto de dados é realizada segundo a metodologia:

\section{Dados de entrada: sismogramas de campo}

$\hat{u}\left(x, y, z=0, t ; f_{n}\right)$,

onde $n=1, \ldots, N_{f}$ (quantidade de fontes).

\section{Construção da família de múltiplas fontes:}

$\tilde{u}(x, y, z, t ; p)=\sum_{n=1}^{N_{f}} \hat{u}\left(x, y, z=0, t-\hat{t}_{n} ; f_{n}\right)$ onde $\hat{t}_{n}=p(x, y)$ representa o atraso considerado para o sismograma relativo à posição de detonação $f_{n}$.

\section{Determinação da matriz de tempo de trânsito $T D$}

A matriz de tempo de trânsito usada na condição de imagem é determinada pelo tempo de chegada da onda de maior amplitude em cada ponto do modelo a partir da detonação das múltiplas fontes. Segundo este critério, a cada passo de tempo $t$, quando o campo em cada ponto $(x, z)$ é recalculado, o algoritmo analisa se o campo nesse novo passo de tempo é maior que o anterior. Caso seja, ele grava este valor como o campo de máxima amplitude $u_{\max }(x, z)$ no ponto $(x, z)$ e atribui este passo de tempo t como a condição de imagem no ponto $(\mathrm{x}, \mathrm{z})$.

\section{Propagação Reversa no Tempo}

A Migração RTM, baseada no princípio da reversibilidade temporal, pode ser resumida como um problema de condição de contorno associado a uma condição de imagem onde a condição de contorno é o registro do campo de pressão feito na superfície pelos geofones ou hidrofones e a condição de imagem, o tempo de trânsito da onda direta (TD) para cada posição do modelo. O sismograma é reinjetado no modelo, a partir do tempo final de registro $\left(t_{f}\right)$ até o tempo inicial de registro $(t=0)$, através dos $M$ receptores. Cada traço, portanto, é injetado como fonte sísmica no receptor que o colheu.

A propagação reversa no tempo da família de múltiplas fontes é realizada através da solução da equação diferencial:

$$
\nabla^{2} u-\frac{1}{v^{2}} \partial_{t t} u=\tilde{u}\left(x, y, z=0, t_{f}-t ; p\right)
$$

onde $t_{f}$ representa o tempo final de registro.

\section{Imposição da Condição de Imagem}

A migração de cada registro de múltiplas fontes para atrasos definidos por $p$ é dada por:

$$
m(x, y, z ; p)=u(x, y, z, t=T D(x, y, z ; p)) .
$$

Para várias famílias de múltiplas fontes, o resultado final da migração é dado por:

$$
M(x, y, z)=\sum_{n=1}^{M} m\left(x, y, z ; p_{n}\right)
$$

onde $\boldsymbol{M}$ denota o número de famílias de múltiplas fontes. 
Tabela 1 - Parâmetros utilizados na modelagem e migração dos dados.

\begin{tabular}{|c|c|}
\hline Modelo & Overthrust \\
\hline Dimensões $(\mathrm{x}, \mathrm{y}, \mathrm{z})$ & $10 \times 10 \times 2,35 \mathrm{Km}$ \\
\hline $\mathrm{Nx}, \mathrm{Ny}, \mathrm{Nz}$ & $401 \times 401 \times 94$ \\
\hline $\mathrm{DT}$ & $2 \mathrm{~ms}$ \\
\hline $\mathrm{DX}=\mathrm{DY}=\mathrm{DZ}$ & 25 \\
\hline Tempo de registro & $3,6 \mathrm{~s}$ \\
\hline Frequência da Fonte & $50 \mathrm{~Hz}$ \\
\hline
\end{tabular}

\section{Resultados}

O modelo de velocidade escolhido para aplicação da técnica de imageamento descrita acima foi o Overthrust (Figura 1) proposto pela SEG/EAGE. Este modelo possui dimensões de $20 \times 20 \times 3,5 \mathrm{Km}$. Apresenta vários graus de complexidade geológica com um total de 17 camadas que representam uma zona de empurrão e ainda canais entrelaçados com algumas lentes em algumas camadas (Weimer e Davis, 1996).
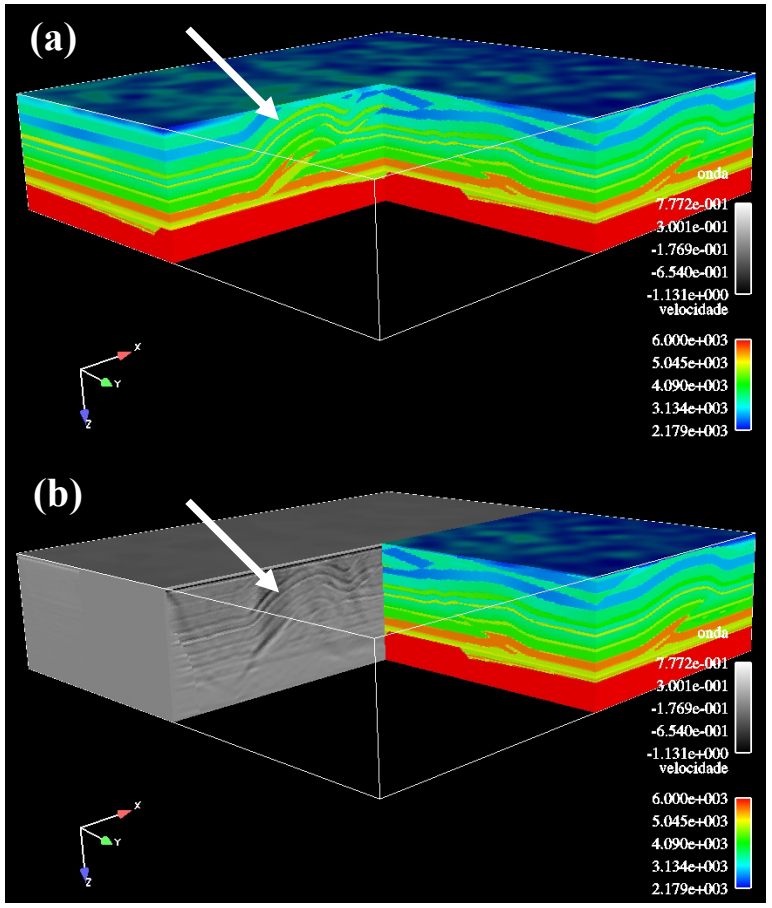

Figura 1. Cubo de velocidade Overthrust SEG/EAGE.

Comparando-se com a Figura a com a b, pode-se que ver que a região de empurrão foi imageada com sucesso.

A Figura 1a apresenta uma visão ampla do modelo de velocidade e, em especial, uma das regiões mais complexas destacada pela seta, que é a zona de

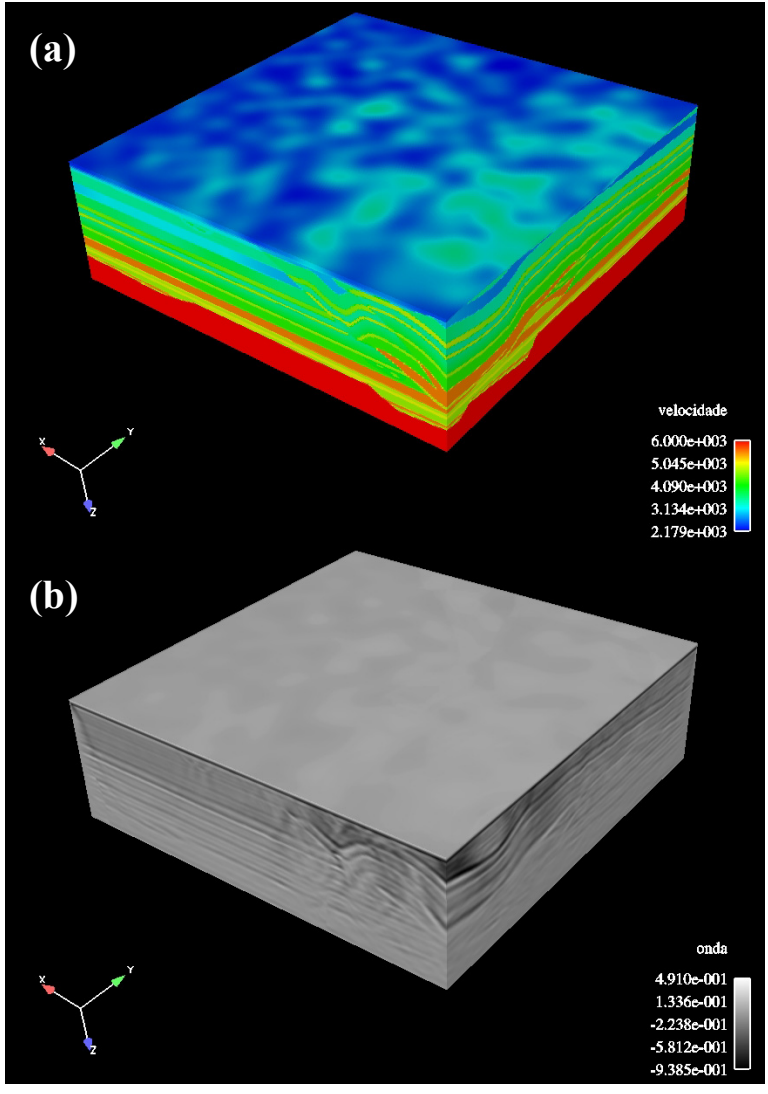

Figura 2. a) Parte do cubo de velocidade; b) Cubo de velocidade migrado.

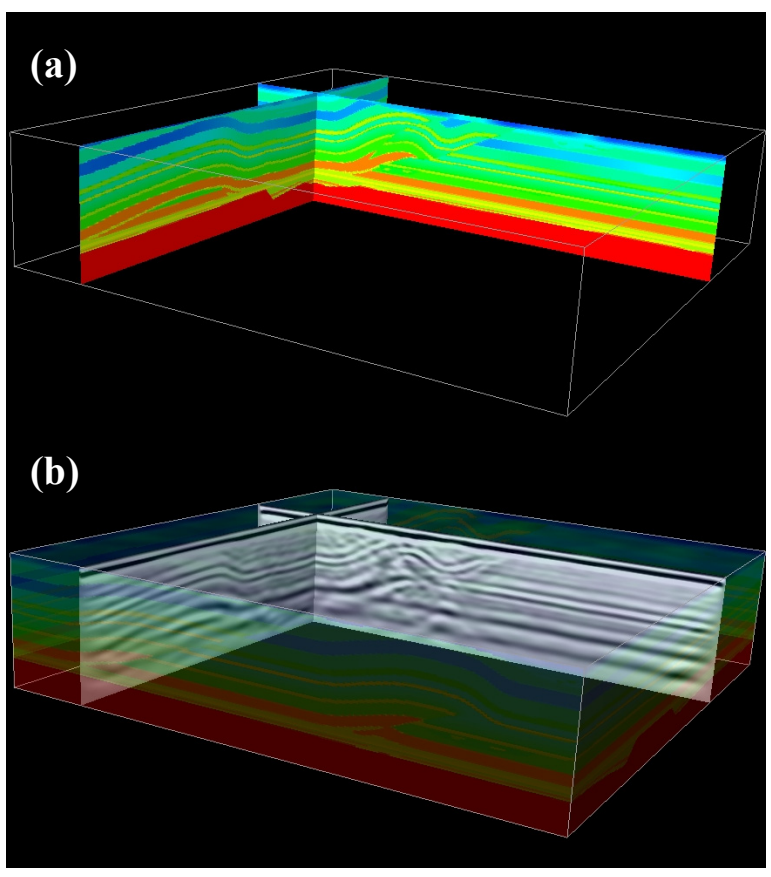

Figura 3. Cortes "inline" e "crossline" no modelo de velocidade (a) e no cubo migrado (b). 

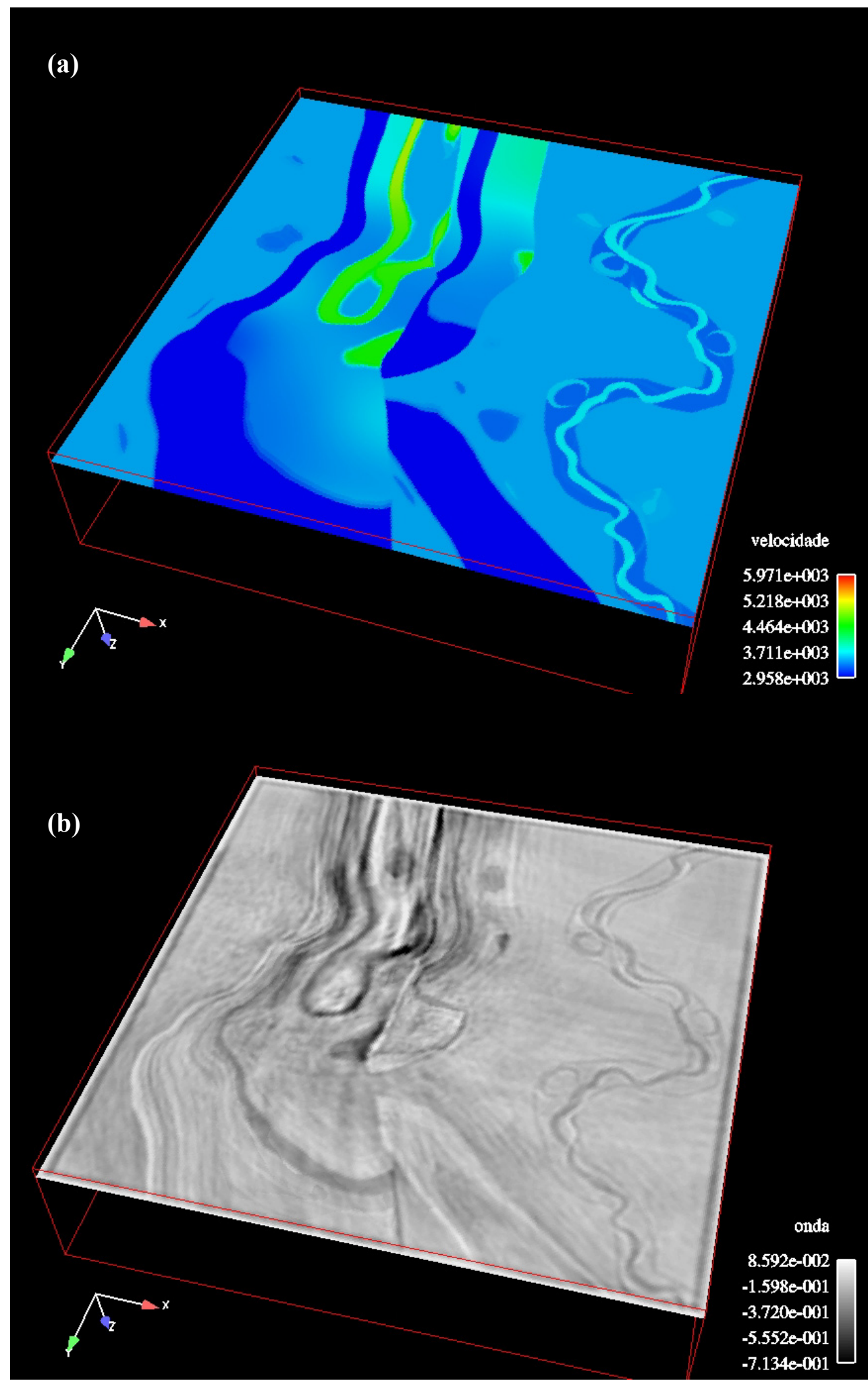

Figura 4. Corte no eixo Z ("slice") no modelo de velocidade (a) e no cubo migrado (b). Fica clara a identificação tanto das falhas como dos paleocanais e lentes existentes no modelo original. 
empurrão. A Figura $1 \mathrm{~b}$ apresenta parte do modelo migrado junto com o modelo de velocidade.

A Figura 2a apresenta uma parte reduzida do modelo de velocidade e na Figura $2 b$ o cubo migrado. $O$ objetivo foi mostrar nas faces laterais o interior do modelo. A Figura 3 apresenta cortes "inline" e "crossline" tanto do modelo de velocidade (Figura 3a) quanto do cubo migrado (Figura $3 b$ ).

Um resultado surpreendente foi encontrado ao realizar "slices" em profundidade apresentados na Figura 4. O imageamento dos paleocanais e lentes, tanto quanto a complexa região de falhas do modelo de velocidade (Figura 4a), puderam ser observados com bastante evidência no cubo migrado (Figura $4 b$ ).

A modelagem e o imageamento realizados neste trabalho foram processados em computadores pessoais com CPU OPTRON, $2.6 \mathrm{GHz}$ e $4 \mathrm{~GB}$ de RAM. O esquema para visualização $3 \mathrm{D}$ foi possível através do desenvolvimento de rotinas computacionais para o uso do software ENSIGHT GOLD como proposto por Silva et al. (Silva, 2006).

\section{Conclusões}

Os resultados mostraram que o uso da migração reversa no tempo associada à técnica do registro de múltiplas fontes é uma ferramenta poderosa para o imageamento de estruturas geológicas complexas, principalmente em se tratando de levantamento sísmico $3 \mathrm{D}$, onde o grande volume de dados pode encarecer em muito o custo computacional quando apenas técnicas convencionais são utilizadas. A boa resolução obtida e o baixo custo computacional são fatores relevantes para o incentivo do uso e desenvolvimento de tecnologias que contemplem este tipo de técnica de imageamento, como delayed shot gather, common focus point, dentre outras.

\section{Referências}

BERKHOUT, A. J., 1992. "Areal shot-record technology", J.Seis.Expl.1, n.3, 151-264.

BOTELHO, M. A. B, STOFFA, P. L., 1988, "Velocity analysis using Reverse Time Migration", Presented at the AGU annual meeting.

CUNHA , P.E.M., PALERMO, L.A.C., 2003, "A Multi-source" version of the Reverse Time Migration (RTM)". Apresentado no $8^{\text {th }}$ International Congress of the Brazilian Geophysical Society.

SILVA, J.J., 2002, "Migração Reversa no Tempo: resolução Sísmica Interpoços". Tese de Mestrado, COPPE/UFRJ.

MOREIRA, C.A., 2004, "Migração pré-empilhamento em profundidade utilizando ondas planas", Tese de Doutorado, UFBA, Bahia, Brasil.

WEIMER, P. e DAVIS, T., 1996, "Applications of 3-D Seismic Data to Exploration and Production", SEG Geophysical Developments Series, AAPG Studies in Geology No. 42.
SILVA, J. J. et al., 2006, "2D and 3D visualizations of seismic wave propagation". International Workshop on Applied Modeling and Simulation, Búzios, RJ.

ZEITLIN, M. J., 2001. "How 3-D visualization will change interpretation strategies in future oil companies". The Leading Edge, December, 2001. Pg. 1370.

FARIA, E. L., 1986. 1986, "Migração antes do empilhamento utilizando propagação reversa no tempo". Tese de mestrado - UFBA, Bahia - Brasil.

ZHANG, G. e SHAN, G., 2003, "Prestack migration of areal shot records with mix phase encoding". SEG Technical Program Expanded Abstracts - pp. 1031-1034. 
Il Simpósio Brasileiro de Geofísica

II Simpósio Brasileiro da SBGf - Natal 